\title{
APPLICABILITY OF INNOVATIVE BUILDING MATERIALS FOR WALL STRUCTURES TO MAXIMISE THE ENERGY EFFICIENCY OF BUILDINGS IN SRI LANKA
}

\author{
SALGADU M. D. R. S. ${ }^{1}$, DEVAPRIYA K. D. K. ${ }^{2} \&$ GOWSİGA M. ${ }^{3}$ \\ Department of Building Economics, University of Moratuwa, Sri Lanka. \\ 1dinithisalgadu@gmail.com, 2devahku@yahoo.com,3gowsigam@uom.lk
}

\begin{abstract}
The $\mathrm{CO}_{2}$ emission is increased globally and the building sector is playing as the major industry with approximately a half percent. The carbon emission of building materials is directly affected by the energy efficiency of the building. Energy has become a limited resource in the whole world and all the sectors try to minimise their consumption to overcome the energyrelated issues. Also, the selection of building materials for wall structure is playing a major role due to the highest surface area, to make a better indoor environment within the specified and required level of performance. As a result, Innovative Building Materials (IBMs) for wall structure has emerged. Even though it is currently practiced worldwide, it is not much familiar in Sri Lanka. Therefore, this research aims to identify the applicability of IBMs for wall structures of buildings in Sri Lanka. Primarily, a comprehensive literature survey was done. Three expert semi-structured interviews were carried out for the pilot survey as the foundation for data collection. Then, a questionnaire survey was done among building-related professionals and collected data were analysed using the Relative Important Index (RII). As the finding result, hollow blocks and EPS wall panels only familiarising in Sri Lanka. Finally, challenges and strategies to overcome when selecting IBMs for the wall were recognized.
\end{abstract}

Keywords: Innovative building materials; wall structures; energy efficiency; Sri Lanka.

\section{Introduction}

Greenhouse gas emission and environmental damage are increasing with the globalization and development of the construction industry where significant usage of energy resources and energywasting is happened (Liu \& Mi, 2017). Further, the authors mentioned that buildings involve a double impact on the environment when they consume energy around 40\% while emitting greenhouse gasses in 30\% worldwide. The higher ranked $\mathrm{CO}_{2}$ emission sector is buildings as $46.7 \%$ and building materials are performing the main role in the building sector to emitting $\mathrm{CO}_{2}$ to the environment (Cantor \& Manea, 2014). When energy has become a limited resource in the whole world, all the sectors which are consuming energy trying to minimise their energy consumption due to the issues such as increasing of energy demand in worldwide, energy security, increasing of energy cost, and requirement of reducing environmental damage (Gratia \& Herde, 2004). Also, most of the resources are consisting of carbon in this century. However, it has resulted in high $\mathrm{CO}_{2}$ emission and environmental pollution which is led to global warming (Aurangzed \& Jana, 2016). Also, when the carbon emission is high, the energy efficiency of the building goes down (Kumanayake, et al., 2018). Thus, to mitigate this problem all the countries try to minimise the usage of high carbon emission materials for construction purposes and as a result, Innovative Building Materials (IBMs) have been considered under the green building concept (Arun, 2013). There is a number of ways to maintain the required level of indoor thermal comfort and energy consumption in buildings by using IBMs instead of traditional building materials (Gracia \& Cabeza, 2015). Therefore, the selection of building materials is playing a major role to make a better indoor environment within the specified and required level of performance (Gracia \& Cabeza, 2015). Building materials that are reclaimed by reusing, recycling, reducing and, low impact on the environment are considered as green material (Hsiou, et al., 2016).

These IBMs can be developed by using plant fibers, recycled, and reusable wastes, phase change materials and photochromic glass to maximise the passive energy-efficiency of buildings (Miami University, 2005). There are many experiments conducted for designing more energy efficient building materials (Javanovic, 2017) and the lifecycle energy effect should be considered when 
designing and developing innovative materials (Kuijk, et al., 2018). A building consists of many elements such as foundation, wall, roof, floor, doors, and windows with their unique functionalities (Flores, et al., 2019). Primarily, compared to the other building elements, the wall has the highest surface area which can be effectively used to saving energy by using IBMs for the wall. According to Merwe (2012), the external wall is used as a thermal resistant element to the building which helps to maximize energy efficiency with natural warming and cooling by reducing cost related to mechanical warming and cooling in the building (Merwe, 2011). There are many numbers and variety of building materials used for wall structure worldwide, both, natural and manmade (Jaehun \& Jehean, 2016).

When it comes to the Sri Lankan context, there is a need of utilizing innovative materials to conserve energy. To promote using energy-efficient building materials, government authorities are followed some codes and standards to provide a guide to building material selection and promoting constructors to use energy efficient building materials (SLSEA, 2009). Even though fewer of IBMs are used in Sri Lanka and there are no sufficient strategies to maximise the energy efficiency of buildings for using IBMs which are practiced worldwide. However, there is a research gap between IBMs usage for walls and maximising energy efficiency. Hence, this study aims to identify the applicability of IBMs for wall structures of buildings in Sri Lanka, The structure of this paper begins with literature synthesis and continues with the method of study. Then, research findings and discussion and ended up with a conclusion.

\section{Literature Synthesis}

Day by day demand for energy in the world pursues scholars and researchers to pave the way for a positive change along with innovative replacement option (Danish, et al., 2018). Also, the learning process and technology go towards innovations that can be achieved many perspectives (Tangkar \& Arditi, 2000). Furthermore, the authors said that along with many years with the time invisible environmental damage was increased while the construction industry is looking for innovative solutions. Additionally, reducing inside air temperatures, releasing fewer pollutants, improving air quality, saving energy, and increasing the comfort of residents in buildings are beneficial for the use of IBMs (Aslani, et al., 2018). Thus, the following table 1 shows a summary of some IBMs for walls.

Table 1 Innovative Building Materials for Walls

\begin{tabular}{|c|c|}
\hline Materials & Descriptions \\
\hline Insulated Wall & $\begin{array}{l}\text { Designed to minimise the energy consumption of buildings in a higher level of } \\
\text { external heated area, decrease thermal bridge effect and maximise the cost- } \\
\text { effectiveness of buildings. (Jaehun \& Jehean, 2016). }\end{array}$ \\
\hline Trombe Wall & $\begin{array}{l}\text { It is constructing as a } 20-40 \mathrm{~cm} \text { thick thermal wall fixed to the brick or concrete } \\
\text { wall to effectively use of energy for heating and ventilation (Jovanovic, et al., } \\
\text { 2017). }\end{array}$ \\
\hline $\begin{array}{l}\text { Phase Change Material } \\
\text { (PCM) }\end{array}$ & $\begin{array}{l}\text { The inclusion of PCM in the concrete structure reduces the effect of outdoor } \\
\text { temperature variations on the indoor surface temperature. } \\
\text { This is due to the higher heat storage capacity and lower thermal conductivity of } \\
\text { MPCM-concrete. Concrete used in PCM heat resistance level is decreased } \\
\text { compared to the normal concrete due to the heat storage property of the material. } \\
\text { That can be make the cooling zone inside the building with lower heat } \\
\text { temperature and outdoor will keep remaining heat zone (Cao, et al., 2018). }\end{array}$ \\
\hline Hollow Blocks & $\begin{array}{l}\text { There are cavities inside the block to transfer the heat through the block, it is } \\
\text { helped to maintain the proper ventilation inside the building with the proper } \\
\text { relationship with the outside of the building to improve the energy performance of } \\
\text { the building (Mohammad, et al., 2011: Maskell, et al., 2018). }\end{array}$ \\
\hline Recycling Green & These are designed using renewable energy sources, Recycled plastics, polythene, \\
\hline
\end{tabular}




\begin{tabular}{|c|c|}
\hline Building Materials & $\begin{array}{l}\text { papers, fibre, timber, and rubber can be used as recycling green building material } \\
\text { to the building projects (Chang, et al., 2016). }\end{array}$ \\
\hline $\begin{array}{l}\text { Bamboo Scrimber And } \\
\text { Laminated Bamboo }\end{array}$ & $\begin{array}{l}\text { Bamboo is using as building material to the wall since history, but compared with } \\
\text { the strength and heat of other materials, using pure bamboo was reduced. Thus, } \\
\text { treated bamboo was detected. The bamboo scrimber and laminated bamboo are } \\
\text { heavily processed before testing. In particular, the impact of heat treatment } \\
\text { performed on the material to achieve a caramel colour. Natural coloured bamboo } \\
\text { will provide a better understanding of the effects of heat treatment on the strength } \\
\text { of the material (Sharma, et al., 2014). }\end{array}$ \\
\hline $\begin{array}{l}\text { Concre } \\
\text { Wheat }\end{array}$ & $\begin{array}{l}\text { Agricultural production leaves behind it a considerable amount of waste; the most } \\
\text { common agricultural waste is wheat straw. It was made of two components which } \\
\text { are plain concrete and wheat straw as reinforcing material. it was proved with } \\
\text { experiment result that there are new opportunities to use agricultural waste as } \\
\text { wheat straw in the development of new construction materials by using wheat } \\
\text { straw new building materials can be realized and obtain similar features as classic } \\
\text { materials (Cantor \& Manea, 2014). }\end{array}$ \\
\hline $\begin{array}{l}\text { Recycled Plastic } \\
\text { Lumber (RPL) }\end{array}$ & $\begin{array}{l}\text { Recycled plastic lumber is made using recycled plastic wastes, helps to reduce } \\
\text { cement contribution and also the solution for plastic wastes. It can be used as } \\
\text { structural as well as the non-structural material. RPL does not lead to corrosion or } \\
\text { insect attack will make sure the durability of the material and non-homogenous } \\
\text { cross-section leads to preparing the cooling process (Herrera, et al., 2018). }\end{array}$ \\
\hline Eco-Wall s & $\begin{array}{l}\text { Paper-based wall systems have been designed recently for the use of interior walls } \\
\text { in commercial buildings (Johnston, et al., 2005). }\end{array}$ \\
\hline $\begin{array}{l}\text { Pollution Absorbing } \\
\text { Bricks }\end{array}$ & $\begin{array}{l}\text { It has a two-layer facade system, with the specialist bricks on the outside and } \\
\text { standard insulation on the inside the breath brick sucks the pollutants in the air } \\
\text { and releases filtered air. In the canter is a cyclone filtration system that separates } \\
\text { out the heavy air particles from the air and collects them in a removable hopper } \\
\text { and design is very similar to a vacuum in which the design of breathing bricks can } \\
\text { be configured in a wall with a window and a cooling system as well. It is a } \\
\text { technology that can be easily applied to the current construction processes (Akbar, } \\
\text { 2019). }\end{array}$ \\
\hline
\end{tabular}

Challengers of using IBMs for wall structure are related to the technical knowledge and awareness among people about innovative projects and products. To gain the technical knowledge and aware people of IBMs, there should be a proper process of communication between researchers, material designers, material suppliers, and end-users (Lee, et al., 2019). Thus, to overcome the challenges of IBMs used to maximise energy efficiency in Sri Lankan buildings can be fulfilled by using strategies. Key areas such as technical, legal, economic, social, and environmental can be taken to make strategies (Matheson, 2019) to enhance the Sri Lankan applicability of IBMs. Many certifications and assessment methods of energy efficiency in buildings are developed worldwide and can be taken legal validation to IBMs design, produce, and usage through those kinds of certification tools. BREEAM, LEED, ISO 2600o, GREENSL rating system, and Eco-labelling system are major tools that can be taken to make strategies to Sri Lankan applicability of IBMs to maximising the energy efficiency of buildings. Moreover, when using IBMs for wall structures it can be certified as an environmental friendly project under the Code of Practice for Energy Efficient Buildings in Sri Lanka was compiled by the Sri Lanka Sustainable Energy Authority (SLSEA) upon reviewing and amending the Energy Efficient Building Code (SLSEA, 2009). Institute of Eco-Labelling (LIOE) under the Sri Lanka Green Building Council is issuing "Eco-Labelling" for sustainable building materials to promote local manufactures to design building materials with green features and promoting the usage of green building materials under the certification (GBCSL, 2019). 


\section{Research Method}

The aim of this study is to identify the applicability of IBMs for wall structures of buildings in Sri Lanka. Primarily, a comprehensive literature review was conducted to collect a foundation knowledge on the topic and a quantitative approach was selected to continue the research to check the applicability of the literature finding to the Sri Lankan context. Then, three expert semi-structured interviews were carried out for the pilot survey to validate the findings of the literature review and finalise the questionnaire. A questionnaire survey was designed and distributed directly and via email. The sample was selected according to the involvement level of the profession to the IBMs usage in the buildings. The target population is 45 and the sample composition is architects, Civil Engineers, Building Material Designers, Product Developers (Building material), and Facilities Managers respectively with the target respondent numbers $12,12,8,8$, and 5 . But the response rate was $82 \%$ and among those respondents, 61\% were being in the building industry in $0-5$ years, due to the innovative and green building sector were developed very recently in Sri Lanka, 22\% were completed 5-10 years while $17 \%$ of 10-20 years of experience. Relative Importance Index (RII) was used as the data analysing technique which could help to rank the factors according to the importance level to the reference. The importance level of the RII categorized into seven levels to analyse data more sensitively due to some factors were differed at a minor level. Those seven RII value ranges with important levels are $0.90 \leq \mathrm{RII} \leq 1$ as Strongly Important, $0.75 \leq \mathrm{RII} \leq 0.89$ as Very Important, $0.60 \leq$ RII $\leq 0.74$ as Important, $0.45 \leq \mathrm{RII} \leq 0.59$ as Moderately Important, $0.30 \leq \mathrm{RII} \leq 0.44$ as Unimportant, $0.15 \leq \mathrm{RII} \leq 0.29$ as Very Unimportant, and $\mathrm{o} \leq \mathrm{RII} \leq 0.14$ Strongly Unimportant.

$$
R I I=\sum W i X i / \sum X i
$$

Where, $\mathrm{Wi}=$ Weight is given to $\mathrm{i}^{\text {th }}$ response, $\mathrm{Wi}=1,2,3,4$ and $5, \mathrm{Xi}=$ occurrence of the $\mathrm{i}^{\text {th }}$ response and $\mathrm{i}=$ response category - 1, 2, 3, 4 and 5 for strongly disagree, disagree, neither agree or disagree, Agree and strongly agree respectively.

\section{Research Findings and Discussion}

This section consists of three sub-sections such as traditional building materials, IBMs, and challenges and strategies.

\subsection{TRADITIONAL BUILDING MATERIALS}

Traditional building materials which are commonly used in Sri Lanka were identified and those materials respectively with RII ranking order such as Brick (0.917), Concrete (0.833), Glass (0.761), Timber (0.611), Plywood (0.606), Gypsum Board (0.517) and Stone (0.506). Accordingly, bricks are used as the building material for wall structure in Sri Lanka most of the time. In conclusion, there is no material under 0.44 and all are above 0.505 . It can be validated that above mentioned seven materials are currently using in the building projects in Sri Lanka. Table 2 illustrate the ranking of the reason for the selection of these building materials. Among that, six were identified through literature and validated in the pilot survey. Moreover, availability in the market and appearance were added in the pilot survey.

Plywood is widely used as a building material for partition walls these days in Sri Lanka due to its unique characteristics. Timber is a high-cost building material but most clients like to the appearance of timber. Therefore, plywood has been designed to overcome those barriers. It is clear that plywood is selected as a secondary solution for timber with availability in the market, low cost, and low maintenance. Gypsum boards are used as interior walls or partition wall material. Most of the professionals are selecting the gypsum board due to the lightweight quality of the material. But in this study weight is not considered as a factor. Therefore, from the other factor gypsum is selected due to 
the low maintenance requirement and low cost rather than having a wall with other material. According to the results of the RII of collected data, energy efficiency is not considered when they selecting Gypsum as a wall material.

Raw materials for the brick manufacturing industry are easier to find in Sri Lanka. Therefore, a wide variety of bricks are easier to find in the Sri Lankan market. That is the main reason for selecting brick as wall material by many professionals which are consisted of strongly important RII. Also, the cost is also lower when compared to other factors. However, Glass has low energy efficiency than others due to thermal radiation are directly affected as heat gain through the glass and it is led to high air conditioning cost.

Table 2 Reasons for the selection of building materials (Traditional \& Innovative Building Materials)

\begin{tabular}{|c|c|c|c|c|c|c|c|c|c|c|c|c|c|c|c|c|c|}
\hline \multirow[t]{3}{*}{ No } & \multirow[t]{3}{*}{ Reason } & \multicolumn{14}{|c|}{ Traditional Building Materials } & \multicolumn{2}{|c|}{ IBMs } \\
\hline & & \multicolumn{2}{|c|}{ Concrete } & \multicolumn{2}{|c|}{ Timber } & \multicolumn{2}{|c|}{ Plywood } & \multicolumn{2}{|c|}{$\begin{array}{c}\text { Gypsum } \\
\text { board }\end{array}$} & \multicolumn{2}{|c|}{ Stone } & \multicolumn{2}{|c|}{ Brick } & \multicolumn{2}{|c|}{ Glass } & & \\
\hline & & RII & Rank & RII & Rank & RII & Rank & RII & Rank & RII & Rank & RII & Rank & RII & Rank & RII & Rank \\
\hline $\mathbf{1}$ & $\begin{array}{l}\text { Structural } \\
\text { Strength }\end{array}$ & 0.917 & 1 & 0.572 & 5 & 0.344 & 8 & 0.506 & 7 & 0.978 & 2 & 0.817 & 3 & 0.411 & 5 & 0.85 & 2 \\
\hline 2 & High Durability & 0.894 & 2 & 0.544 & 6 & 0.417 & 5 & 0.511 & 5 & 0.989 & 1 & 0.794 & 4 & 0.672 & 3 & 0.872 & 1 \\
\hline 3 & $\begin{array}{l}\text { Low } \\
\text { Maintenance }\end{array}$ & 0.878 & 3 & 0.4 & 8 & 0.667 & 3 & 0.533 & 1 & 0.872 & 5 & 0.722 & 5 & 0.294 & 8 & 0.778 & 5 \\
\hline 4 & Low Cost & 0.833 & 4 & 0.478 & 7 & 0.689 & 2 & 0.517 & 2 & 0.300 & 8 & 0.861 & 2 & 0.600 & 4 & 0.822 & 3 \\
\hline 5 & $\begin{array}{l}\text { Availability in } \\
\text { the market }\end{array}$ & 0.828 & 5 & 0.744 & 3 & 0.844 & 1 & 0.511 & 4 & 0.744 & 6 & 0.972 & 1 & 0.944 & 1 & 0.767 & 6 \\
\hline 6 & $\begin{array}{l}\text { Environmental } \\
\text { Friendly }\end{array}$ & 0.689 & 6 & 0.767 & 2 & 0.372 & 7 & 0.511 & 6 & 0.978 & 3 & 0.600 & 8 & 0.300 & 7 & 0.661 & 8 \\
\hline 7 & $\begin{array}{l}\text { Energy } \\
\text { Efficiency }\end{array}$ & 0.650 & 7 & 0.628 & 4 & 0.400 & 6 & 0.506 & 8 & 0.642 & 7 & 0.606 & 7 & 0.333 & 6 & 0.822 & 4 \\
\hline 8 & Appearance & 0.644 & 8 & 0.917 & 1 & 0.417 & 4 & 0.517 & 3 & 0.956 & 4 & 0.717 & 6 & 0.911 & 2 & 0.733 & 7 \\
\hline
\end{tabular}

Thus, selecting building materials for wall structure mainly consider the structural strength and durability of the materials. The professionals who are working on selecting building materials activities, select bricks and concrete as wall material for their projects in Sri Lanka. According to the results of the reasons for selecting wall building materials, there is no strong importance for energy efficiency. Most of the professionals are focusing on cost, market availability, and structural strength as basic functions when selecting materials for wall structures in Sri Lanka.

Other than the properties of the material there can be used other methods affected by selecting the building materials for the wall structure. The pilot survey findings have been included the main five methods for selecting building materials for wall structure in the RII ranking respectively such as Client's requirements (0.922), Evaluate Life cycle cost (0.778), Heat gain calculation (0.5), According to building materials rating system (0.467) and Embodied energy calculation (0.411). Accordingly, the client's requirement is a strongly important factor that is highly considered compared to the other methods. Evaluate life cycle costs can be considered as a very important factor. Other all three methods are indicated that the energy efficiency of the building was considered during the building material selection stage. But heat gain calculation and building material rating system given by the green building council are considered moderately important. According to the findings of the literature review, embodied energy calculation should be calculated before selecting a building material. But RII for embodied energy calculation can be revealed as 0.411 that is indicated as an unimportant factor for respondents. According to the findings of the pilot survey, most of the professionals are considered about properties of the materials and then analysing LCC to matching the client's cost-benefit requirement. 


\subsection{INNOVATIVE BUILDING MATERIALS}

In the Sri Lankan context, how professionals familiar with the IBMs for wall structure was identified through the questionnaire. Many projects used hollow blocks and EPS wall panels as an innovative material for wall structure to minimise the energy consumption in the building which most of the respondents were involved in. The Eco wall system which was identified in the literature review is used moderately. Bamboo and laminated bamboo, Concrete mixed with wheat straw, recycled plastic lumber, and Trombe wall are not much familiar with Sri Lankan practice. Building materials designers and material developers are familiar with those materials, but when it comes to the applicability, there is less motivation towards those materials. Table 3 shows the RII value of those identified innovative building Material usage for the wall structure.

Table 3 RII of innovative Building Materials

\begin{tabular}{llll}
\hline No & Material & RII & Rank \\
\hline $\mathbf{1}$ & Hollow blocks & 0.672 & 4 \\
\hline $\mathbf{2}$ & EPS wall panels & 0.600 & 7 \\
\hline $\mathbf{3}$ & Eco-wall system & 0.450 & 10 \\
\hline $\mathbf{4}$ & Bamboo scrimber and laminated bamboo & 0.439 & 11 \\
\hline $\mathbf{5}$ & Concrete mixed with wheat straw & 0.439 & 12 \\
\hline $\mathbf{6}$ & Recycled plastic lumber (RPL) & 0.333 & 13 \\
\hline $\mathbf{7}$ & Trombe wall & 0.317 & 14 \\
\hline $\mathbf{8}$ & Phase change material & 0.294 & 15 \\
\hline
\end{tabular}

In the literature review, there were identified why nowadays people looking for IBMs. It was not revealed that only focusing on energy efficiency without fulfilling other properties. According to the RII ranking energy efficiency can be identified as a very important factor (Refer to Table 3). Energy efficiency is highly considered when selecting IBMs other than selecting traditional building materials for the wall structure. When ranking both traditional building materials and IBMs usage higher ranks are taken from the traditional building materials (Refer to Section 4.1 \& Table 3). Moreover, according to the response, there were identified $52 \%$ of respondents had been identified there was a major impact on energy efficiency after using innovative building material for their building projects and only $4 \%$ had been not identified any noticeable changes in energy efficiency using IBMs for the wall structure. Also, 37\% and 4\% respectively stated as significant impact and minor impact on energy efficiency after using the IBMs for the wall structure. Additionally, In Sri Lanka hollow blocks and EPS, wall panels are used as the energy-efficient building material for wall structure when all other IBMs which are taken into this study are located in the lowest RII rate compared to the traditional building materials used for wall structure (Refer Table 2). When it is considered about the energy efficiency level of traditional building materials with IBMs, results were revealed that IBMs are much more energy-efficient than traditional building materials. Therefore, there should have been strategies to fill the gap by overcoming the challenges of using IBMs for the wall structure.

\subsection{CHALLENGES AND STRATEGIES}

The following subsection describes the challenges for using innovative building material in Sri Lanka and strategies to overcome those challenges respectively.

\subsubsection{Challenges}

According to the results of the familiarity of innovative building material for wall structure, there are some challenges when thinking about Sri Lankan applicability. Therefore, it should be focused on following challengers, which are stated in Table 4, especially by innovative building material designers and developers, Architects, Engineers, and Facilities managers as specialist professionals in the 
industry. Moreover, there are a limited number of standards related to IBMs such as Green building certificates, Eco-labelling system, ISO 9001, and LEED standards. When compared to the knowledge of traditional building materials, awareness for innovative buildings and searching for IBMs are not much considered in Sri Lanka. Therefore, the lack of information availability has been challenged for peoples who are looking for IBMs. Only $36 \%$ of the respondents mentioned that having awareness of the standards related to IBMs.

Table 4 Challenges for using innovative building materials in Sri Lanka

\begin{tabular}{lll}
\hline No. & Material & RII \\
\hline $\mathbf{1}$ & Lack of technological knowledge on innovative materials usage & 0.906 \\
\hline $\mathbf{2}$ & Difficulty of finding local suppliers & 0.894 \\
\hline $\mathbf{3}$ & Lack of standards for innovative building materials & 0.889 \\
\hline $\mathbf{4}$ & Not aware of maximising energy efficiency through wall materials usage & 0.828 \\
\hline $\mathbf{5}$ & Limited amount and quality of information & 0.828 \\
\hline
\end{tabular}

The strongly important challenge can be validated as a lack of technological knowledge on innovative materials usage. If construction parties are not familiarised with the technology related to the innovative materials they should use, maybe they cannot fulfill the requirements of designers and developers who introducing IBMs. Also, there are some clients who are looked for maximising energy efficiency by using IBMs but difficult to find a local supplier.

\subsubsection{Strategies}

After identifying the challenges of using IBMs, strategies to overcome those challenges were identified in the literature review, and then get experts' opinions on those factors. There were identified some key factors through the findings of the pilot survey. RII was calculated for all the strategies under the main five categories such as technical, legal, economic, social, and environmental. And which are shown in Table 5. The lowest RII is for the BREEAM assessment method when Sri Lankan professionals were not very familiar with the BREEAM which is governed by the Building Research Establishment (BRE).

Table 5 Strategies to overcome the identified Challengers

\begin{tabular}{llll}
\hline \multirow{2}{*}{ Technical } & Strategy & RII & Rank \\
\cline { 2 - 4 } & Durability and structural strength & 0.828 & 1 \\
\cline { 2 - 4 } & Design for resources efficiency & 0.811 & 2 \\
\cline { 2 - 4 } & Continuous maintenance & 0.767 & 3 \\
\cline { 2 - 4 } & Aesthetic appearance & 0.694 & 4 \\
\cline { 2 - 4 } & Fire protection & 0.556 & 5 \\
\cline { 2 - 4 } & Functionality & 0.539 & 6 \\
\hline \multirow{2}{*}{ Eegal } & Eco-Labelling system & 0.722 & 1 \\
\cline { 2 - 4 } & LEED & 0.706 & 2 \\
\cline { 2 - 4 } & GREENSL rating system & 0.683 & 3 \\
\cline { 2 - 4 } & ISO 260oo & 0.526 & 4 \\
\cline { 2 - 4 } & BREEAM & 0.478 & 5 \\
\hline \multirow{2}{*}{ Economical } & Increase profitability & 0.867 & 1 \\
\cline { 2 - 4 } & Increase productivity & 0.834 & 2 \\
\cline { 2 - 4 } & Sustainable procurement & 0.572 & 3 \\
\hline Social & Human safety & 0.844 & 1 \\
\cline { 2 - 4 } & Comfort & 0.739 & 2 \\
\hline
\end{tabular}




\begin{tabular}{llll}
\hline & Awareness & 0.766 & 3 \\
\hline \multirow{2}{*}{ Environmental } & Avoiding pollution & 0.861 & 1 \\
\cline { 2 - 4 } & Improve energy efficiency & 0.889 & 2 \\
\cline { 2 - 4 } & Using natural/recycled raw materials & 0.744 & 3 \\
\hline
\end{tabular}

Factors in the legal strategies were got low RII compared to the other categories due to the lack of awareness on the standards and certification systems related to energy efficiency practices using building materials. But in general, all the factors of strategies were taken above 0.45 RII, which means all of them are important to the study. Therefore, all the factors can be taken as strategies to overcome those challenges.

\section{Conclusion}

Applicability of IBMs to maximising energy efficiency in buildings is currently practiced worldwide as one of the heat load minimisation methods for a lifetime. A wide area of external and internal surface is covered by the wall structure and most of the building projects are using high carbon emission and lack of energy-efficient materials. Thus, the building sector has been looking for IBMs to maximising the energy efficiency of buildings. Even it is not an acceptable level in Sri Lanka compared to the other developing counties. Also, it is clear that when selecting traditional building materials for projects, energy efficiency was not considered as a major factor. But in the case of IBMs selection, the energy efficiency of the building is focused more. The lack of technological knowledge on IBMs was identified as the major challenge for innovative building materials usage in Sri Lanka. Also, building users are not aware of the characteristics of innovative building material to properly using and maintaining those materials. It may be led to reducing the target outcome of materials. Moreover, it is difficult to find local suppliers for internationally recognized building materials and standards related to energy maximising using building materials are not sufficient in Sri Lanka. Finally, but not least, the initial cost is high due to a lack of government support. To overcome those challenges, some strategies have been identified under the main five categories such as technical, legal, economic, social, and environmental.

\section{References}

Akbar, S., 2019. Ten innovative construction materials that could be revolutionise the industry. [Online] Available at: https://geniebelt.com/blog/10-innovative-construction-materials [Accessed 24 September 2019].

Arun, K., 2013. Advances in the Building Materials for Thermal Comfort and Energy Saving. Recent Patents on Engineering.

Aslani, A., Bakhtiar, A. \& Akbarzadeh, M., 2018. Energy Efficiency Technologies in the Building Envelop; Life Cycle and adaption Assessment. Building Engineering.

Aurangzed, M. \& Jana, A., 2016. Dividing wall column; Improving thermal efficiency, energy savings and economic performance. Applied Thermal Engineering, pp. 1033-1041.

Cantor, D. \& Manea, D., 2014. Innovative building materials using agricultural waste. Tirgu-Mures, Romania, Elsevier Ltd, pp. 456-462.

Cao, V. et al., 2018. Thermal analysis of geopolymer concrete walls containing microencapsulated phase change materials for building. Solar Energy, pp. 295-307.

Chang, Y., huang, P., Chuang, T. \& Chang, S., 2016. A pilot study of the colour performance of recycling green building materials. Building and Environment.

Danish, M. et al., 2018. A managed framework for energy efficient building. Building Engineering, pp. $120-128$.

Flores, J. U. et al., 2019. Thermal performance of walls with passive cooling techniques using traditional materials available in the Mexican market. Applied Thermal Engineering, pp. 1154-1169.

GBCSL, 2020. Green Building Council of Sri Lanka. [Online]

Available at: http://srilankagbc.org/GREEN\%20Labeling\%20System.html [Accessed 21 April 2020 ]. 
Gracia, A. \& Cabeza, F., 2015. Phase change materials and thermal energy storage for buildings. Energy and Buildings, p. 419.

Gratia, E. \& Herde, A., 2004. Natural cooling strategies efficiency in an office.. Energy and Building.

Herrera, J., Bedoya-Ruiz, D. \& Hurtado, J., 2018. Seismic behavior of recycled plastic lumber walls: an experimental and analytical research. Manizales, Colombia, Elsevier Ltd, pp. 566-578.

Hsiou, Y., Huang, P., Chuang, . T. F. \& Chang, S., 2016. A pilot study of the color performance of recycling green building materials. Journal of Building Engineering, pp. 114-120.

Jaehun, S. \& Jehean, S., 2016. The effect of external walls on energy performance of Korean traditional building. Sustainable Cities and Society, pp. 10-19.

Javanovic, X., 2017. Energy Efficiency gain by combination of PV modules and Trombe wall in the low energy building design. Energy and Buildings, pp. 568-576.

Jensen, P., Damgaard, T. \& Kristiansen, K., 2009. The Role of Facilities management in Building Projects. Nertherland, s.n., pp. 6-9.

Jovanovic, J., Sun, X., Stevovic, S. \& Chen, J., 2017. Energy efficiency gain by combination of PV modules and Trombe Wall In the low energy building design. Energy Buildings, 4 May.pp. 568-576.

Kuijk, J., Daalhuizen, J. \& Christiaans, H., 2018. Drivers of usability in product design. Design Studies, Volume 60, pp. 139179.

Kumanayake, R., Luo, H. \& Paulusz, N., 2018. Assessment of material related embodied carbon of an office building in Sri Lanka. Energy and buildings, pp. 250-257.

Lee, S., Hong, S. \& Yu, J., 2019. Automated management of green building material information using web crawling and ontology.. Automation in Construction, pp. 230-244.

Liu, M. \& Mi, B., 2017. Life cycle cost analysis of energy-efficient buildings subjected to earthquakes.. Energy and Buildings, pp. 581-589.

Matheson, M., 2019. 11 Green Building Design Strategies and Measures. 6 Advance Water Efficiency and Conservation Measures. [Online]

Available at: https://www.engineeringexchange.com/profiles/blogs/11-green-building [Accessed 10 September 2019].

Merwe, M., 2011. The importance of external walls in energy efficiency of buildings.

Miami university, O., 2005. Eco-Wall Systems: Using Recycled Material in the Design of Commercial Interior Wall Systems for Buildings. Retrieved from United States Environmental protection Agency:, s.l.: s.n.

Sharma, B., Gatoo, A., Bock, M. \& Ramage, M., 2014. Engineered bamboo for structural applications. Construction and building materials.

SLSEA, 2009. Code of practice for energy efficient buildings in Sri Lanka, Colombo: Sri Lanka Sustainable Energy Authority.

Tangkar, M. \& Arditi, D., 200o. Innovation in the construction industry. 2(2), pp. 96-103. 